\title{
Characterization of a New DC-Glow Discharge Plasma Set-Up to Enhance the Electronic Circuits Performance
}

\author{
A. A. Talab ${ }^{1}$, Ashraf Yahia², M. A. Saudy², M. Elsayed ${ }^{2}$ \\ ${ }^{1}$ Plasma Physics \& Nuclear Fusion Department, Cyclotron Facility, NRC, Atomic Energy Authority, Cairo, Egypt \\ ${ }^{2}$ Physics Department, Faculty of Science, Ain Sham University, Cairo, Egypt \\ Email: *azza_talab@yahoo.com
}

How to cite this paper: Talab, A.A., Yahia, A., Saudy, M.A. and Elsayed, M. (2020) Characterization of a New DC-Glow Discharge Plasma Set-Up to Enhance the Electronic Circuits Performance. Journal of Modern Physics, 11, 1044-1057.

https://doi.org/10.4236/jmp.2020.117066

Received: May 12, 2020

Accepted: July 13, 2020

Published: July 16, 2020

Copyright $\odot 2020$ by author(s) and Scientific Research Publishing Inc. This work is licensed under the Creative Commons Attribution International License (CC BY 4.0).

http://creativecommons.org/licenses/by/4.0/

\begin{abstract}
The (DC-GDPAU) is a DC glow discharge plasma experiment that was designed, established, and operated in the Physics Department at Ain Shams University (Egypt). The aim of this experiment is to study and improve some properties of a printed circuit board (PCB) by exposing it to the plasma. The device consists of cylindrical discharge chamber with movable parallel circular copper electrodes (cathode and anode) fixed inside it. The distance between them is $12 \mathrm{~cm}$. This plasma experiment works in a low-pressure range (0.15 - 0.70 Torr) for Ar gas with a maximum DC power supply of $200 \mathrm{~W}$. The Paschen curves and electrical plasma parameters (current, volt, power, resistance) characterized to the plasma have been measured and calculated at each $\mathrm{cm}$ between the two electrodes. Besides, the electron temperature and ion density are obtained at different radial distances using a double Langmuir probe. The electron temperature $\left(K T_{e}\right)$ was kept stable in range 6.58 to 10.44 $\mathrm{eV}$; whereas the ion density $\left(n_{i}\right)$ was in range from $0.91 \times 10^{10} \mathrm{~cm}^{-3}$ to $1.79 \times$ $10^{10} \mathrm{~cm}^{-3}$. A digital optical microscope $(800 \times)$ was employed to draw a comparison between the pre-and after effect of exposure to plasma on the shaping of the circuit layout. The experimental results show that the electrical conductivity increased after plasma exposure, also an improvement in the adhesion force in the $\mathrm{Cu}$ foil surface. A significant increase in the conductivity can be directly related to the position of the sample surfaces as well as to the time of exposure. This shows the importance of the obtained results in developing the PCBs manufacturing that uses in different microelectronics devices like those onboard of space vehicles.
\end{abstract}

\section{Keywords}

DC Glow Discharge, Paschen Curve, Cold Plasma Characteristics, Double 
Electric Probe, Printed Circuit Board (PCB) Properties, Electronic Plasma Application

\section{Introduction}

The non-thermal plasma, which is also named cold or non-equilibrium plasma, is weakly ionized with electron temperatures of a little $\mathrm{eV}$ and colder ion temperatures [1] [2]. The glow discharge plasma has different luminous and dark zones between cathode and anode as shown in Figure 1. It is produced when a direct current from a DC power supply is applied between these two parallel electrodes to a low-pressure gas [3] [4]. The energy is continuously transferred from a high-voltage DC power source to the electrons originating from the cathode that accelerates absorbing energy from the field, ionizing, exciting and undergoing elastic collisions with heavy particles and other electrons to produce the different zones. The glow discharge owes its name to the fact that plasma is luminous; the luminosity is produced because the electrons gain sufficient energy to generate visible light by excitation collisions which generate photons. Involved in the formation of glow discharges are the formation of restricted electric fields and plasma sheaths at each of the electrodes.

It is important after talking about the principals of producing the Dc glow discharge to refer to the Paschen's law. It is a function of gap length $(d)$ between the two electrodes and the gas pressure $(p)$ [i.e. $V_{b d}=f(P d)$ ]. It describes the electric discharge between two conductive materials and determines the breakdown voltage $\left(V_{b d}\right)$ at which the discharge process starts. Beside that $\left(V_{b d}\right)$ depends on the density and type of the gas, the material of the two electrodes, the gap length between them, and the degree of preexisting ionization [5] [6] [7].

During this work, there are different plasma parameters that were measured and calculated. It was very important to begin with determining these parameters to know the suitable conditions of plasma to exposure printed circuit board (PCB) samples to it. An LCR meter (TEGAM) was used to measure the circuit resistance; a significant increase in the conductivity can be directly related to the position of the sample surfaces as well as to the time of exposure.

The double electric probe (DEP) is the most common probe type which has two identical isolated collectors with equal areas and draws no current from plasma, so it disturbs plasma only at its location [8] [9] [10]. From the slope of the IV characteristic curve of DEP as shown in Figure 2, $k T_{e}$ can be obtained, and then $n_{i}$ is evaluated by using the following equations [4] [11]:

$$
\begin{gathered}
\left.\frac{\mathrm{d} I}{\mathrm{~d} V}\right|_{V=0}=\frac{e}{k T_{e}} \frac{i_{i 1} i_{i 2}}{i_{i 1}+i_{i 2}} \\
i_{i}=\frac{1}{2} e n_{i} A\left(\frac{k T_{e}}{m_{i}}\right)^{0.5}
\end{gathered}
$$

where $\left(i_{i}\right)$ represents the saturation current; $(A=2 \pi r h)$ is the area of the double 


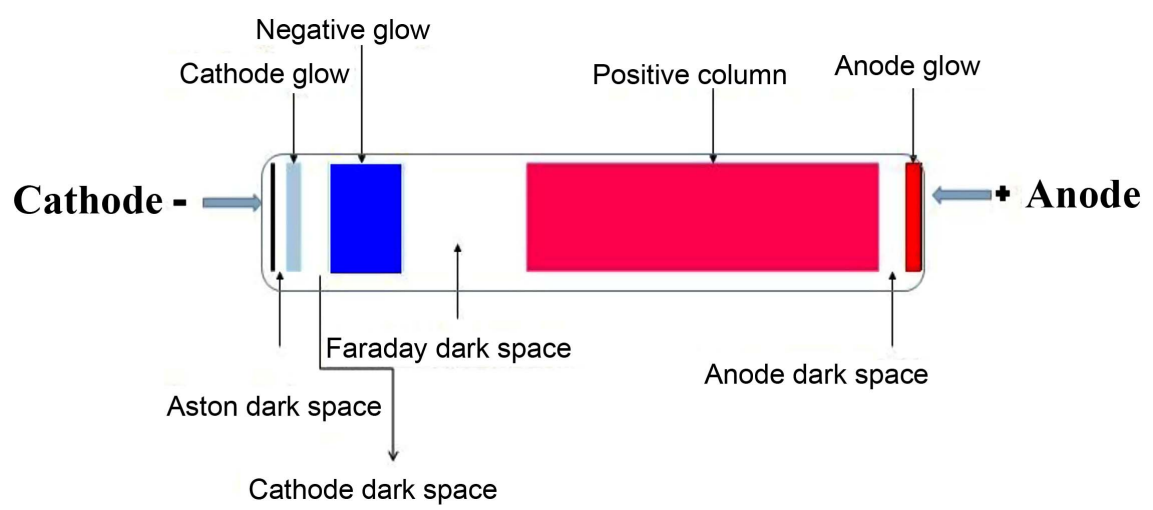

Figure 1. Regions of DC glow discharge plasma as in normal case. It is shown the arrangement of this regions and the area of each one.

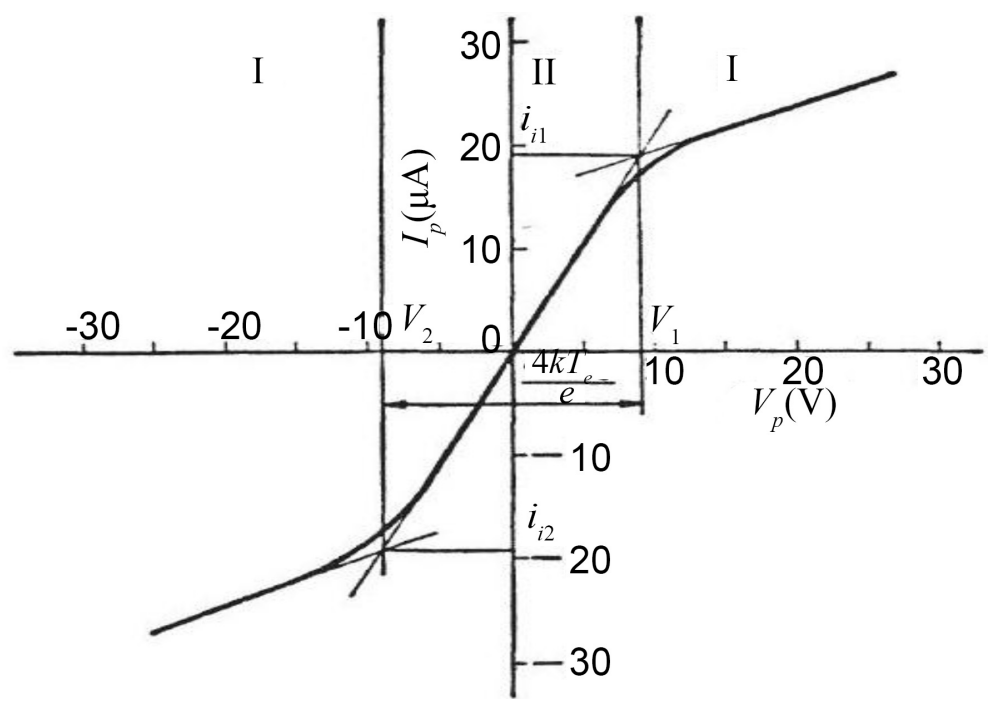

Figure 2. The typical IV characteristic curve of the double probe. It illustrates how $K T_{e}$ is calculated. This curve was drowning from different waveforms which produced from experimental data.

Probe; $r, h$ are the double probe's radius and length; and $\left(m_{i}\right)$ is the ion mass of $\operatorname{Ar}[12]$.

Cold or low-pressure DC glow discharge plasma technology is applied widely in many fields, such as etching, surface treatment and activation, cleaning, electron beam source, sputtering spraying, adhesion improvement, etc. [13] [14] [15]. The adhesive forces bonding is a key joining technology in many manufacturing areas which include the automotive and aerospace industries, adding to biomedical and microelectronics applications [16]. The reactive species (electrons, atomic or molecular ions, atoms or molecules energetically excited) in the cold plasma can modify the superficial functional characteristics of the target material and promote the surface functionalization reactions by generating organic or inorganic thin layers because of the recombination of radicals or molecular fragments species on the surfaces of this material [17] [18] [19].

The printed circuit board (PCB) is a substrate that provides the necessary 
electrical connections for an electronic circuit [20]. And the double layer PCB consists of an insulator layer between two conductive layers that are made of $\mathrm{Cu}$ foil which have excellent electrical and thermal conductivity properties. So, the surface treatment technique by plasma on $\mathrm{Cu}$ foil has become a useful tool to achieve a good adhesion for fine lines with a smooth surface. This is due to the rapid developments in high-frequency and high-speed transmission in electrical wire technology [21] [22] [23].

\section{Experimental Setup}

The DC glow discharge plasma experiment consists of three main parts, a discharge chamber, a vacuum system and an electric circuit. The cylindrical discharge chamber is made of stainless steel with an interior diameter $24.5 \mathrm{~cm}$, a length $12.5 \mathrm{~cm}$ and a thickness $0.9 \mathrm{~cm}$. It consists of two movable circular copper electrodes (cathode and anode) with a diameter $6.5 \mathrm{~cm}$ and a thickness $1 \mathrm{~cm}$ for each one. Where, the anode is left at a fixed location while the cathode moves along an axial length $12 \mathrm{~cm}$.

The vacuum system consists of a rotary vacuum pump to evacuate the system, a needle valve to control the flow of gas, and an analog vacuum gauge controller unit to measure the vacuum and pressure of the gas inside the discharge chamber.

The electric circuit consists of a DC power supply 0 - $5 \mathrm{kV}$ with a DC current $40 \mathrm{~mA}$, a ballast resistor of $10 \mathrm{k} \Omega$ to limit the plasma current and a digital ammeter/voltmeter to measure the plasma current $I_{p}$ and potential $V_{p}$. Adding to a potential divider consists of $50 \mathrm{k} \Omega$ and $22.3 \mathrm{M} \Omega$ resistors connected in series with each other. There is a high voltage probe, to convert the value of power supply voltage by ratio $1 / 1000$, connects with a digital voltammeter to measure the $V_{p s}$

The digital storage oscilloscope (DSO) is connected to a laptop using a USB interface to record the waveform of the breakdown voltage $\left(V_{b d}\right)$ and the waveform of the probe current $\left(I_{\text {Probe }}\right)$. The schematic diagram and setup of the plasma experiment are shown in Figure 3.

The DEP is made of two tungsten wires, each has $0.2 \mathrm{~mm}$ diameter with an equal length of $8 \mathrm{~mm}$ for its two tips and a $4 \mathrm{~mm}$ distance between them. The DEP circuit consists of a variable DC source which gives a probe voltage $V_{\text {Probe }}=$ \pm 40 volts shown in Figure 4 (a). The DEP was placed vertically to the plasma and parallel to the electrodes inside the discharge chamber where it moves in a radial axis at distances $(r=2,4,6$ and $8 \mathrm{~cm})$ from the upper surface of the chamber as shown in Figure 4(b). Figure 4(c) shows some examples of DEP waveforms at $P=0.3$ Torr, $d=3 \mathrm{~cm}, r=6 \mathrm{~cm}$ and $I_{p}=20 \mathrm{~mA}$.

\section{Results and Discussion}

The characterization of the DC glow discharge plasma was determined by three parts, Paschen curves, and electrical plasma parameters, in addition to electron temperature and ion density of the plasma. 


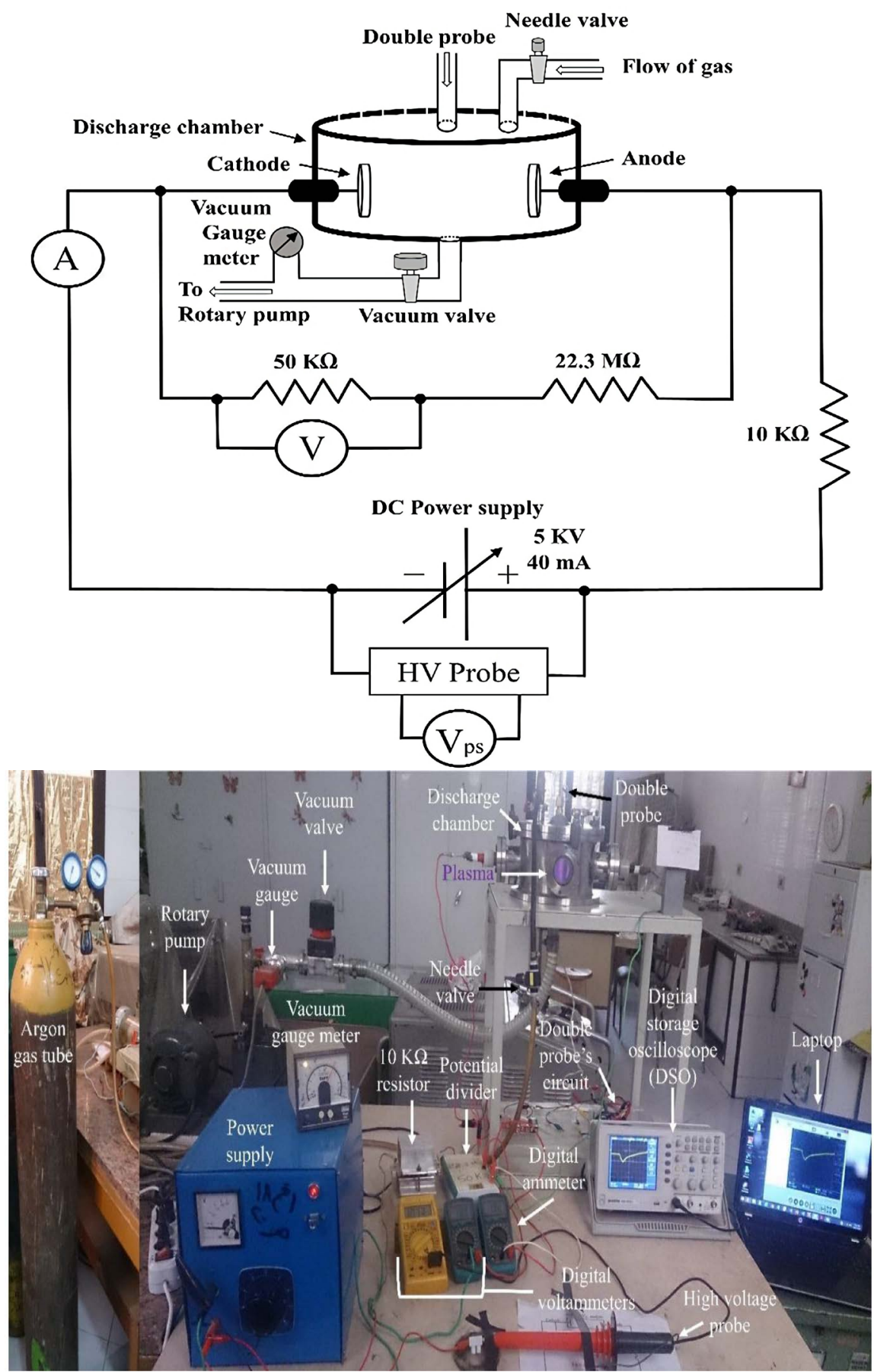

Figure 3. The schematic diagram and the photographic view of the plasma experiment.

The aim of this work is to establish a cold plasma experiment with specifications and characteristics that are in the normal range of previous DC glow discharge plasma experiments in other labs around the world. After validating our experiment, it can use to study the effect of exposing surfaces of different materials to this plasma. Here, the effect of the produced cold plasma on the electrical conductivity and the adhesive forces of a $\mathrm{Cu}$ foil were studied to improve the electronic circuits performance. 


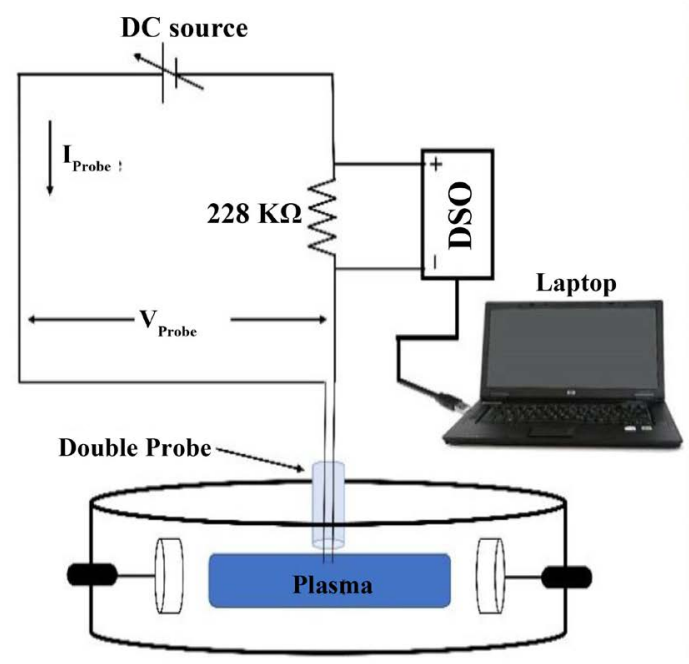

(a)

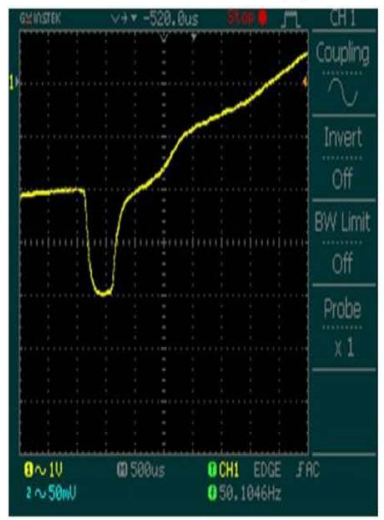

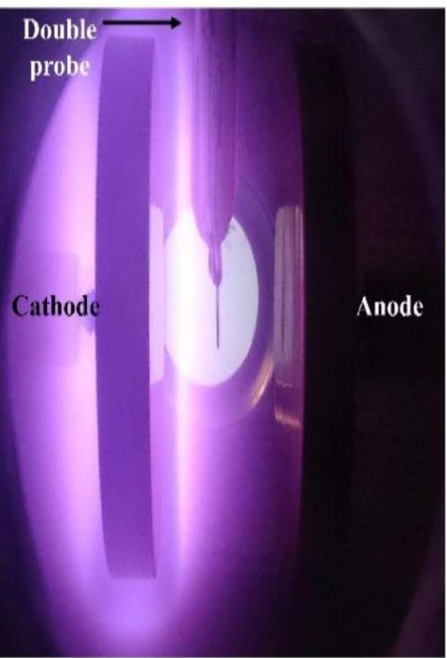

(b)
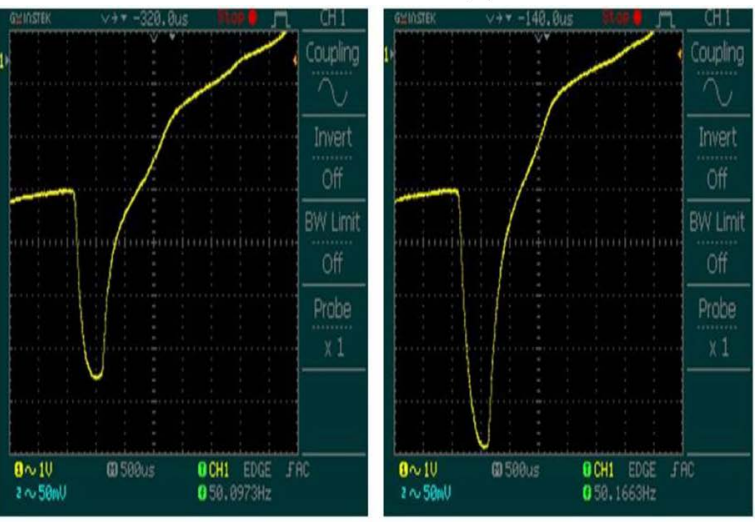

(c)

Figure 4. (a) DEP circuit, (b) DEP inside the plasma chamber, and (c) Examples of the waveform of the double electric probe.

\subsection{Paschen Curves}

The Paschen curves were drawn at different gas pressures $P=0.15$ to 0.70 Torr for each gap length $d=3$ to $7 \mathrm{~cm}$. Figure 5(a) shows the waveform of $V_{b d}$ at $P=$ 0.70 Torr and $d=6 \mathrm{~cm}$, where, once the step of the voltage had occurred, the plasma was generated. Paschen curves at each gap length are shown in Figure 5(b), which cleared that the minimum breakdown voltage occurred at $P=0.3$ Torr.

\subsection{Electrical Plasma Parameters}

The electrical plasma parameters, namely, plasma voltage $V_{p}$, plasma current $I_{p}$, plasma resistance $R_{p}$ and plasma power $W_{p}$ were measured and calculated at each gap length with the operating conditions $P=0.3$ Torr, and $V_{p s}$ varies from 400 to 1800 volt.

The variation curves between the operating voltages $V_{p s}$ with the electrical plasma parameters are shown in Figure 6. From these curves it obvious that:

1) Increasing $V_{p s}$ the number of ionized gas increased which resulted in 


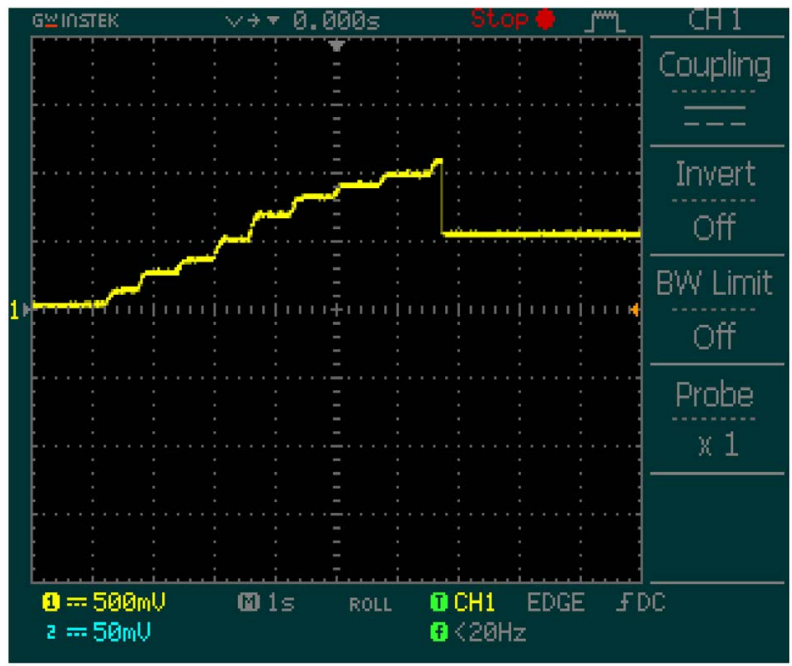

(a)

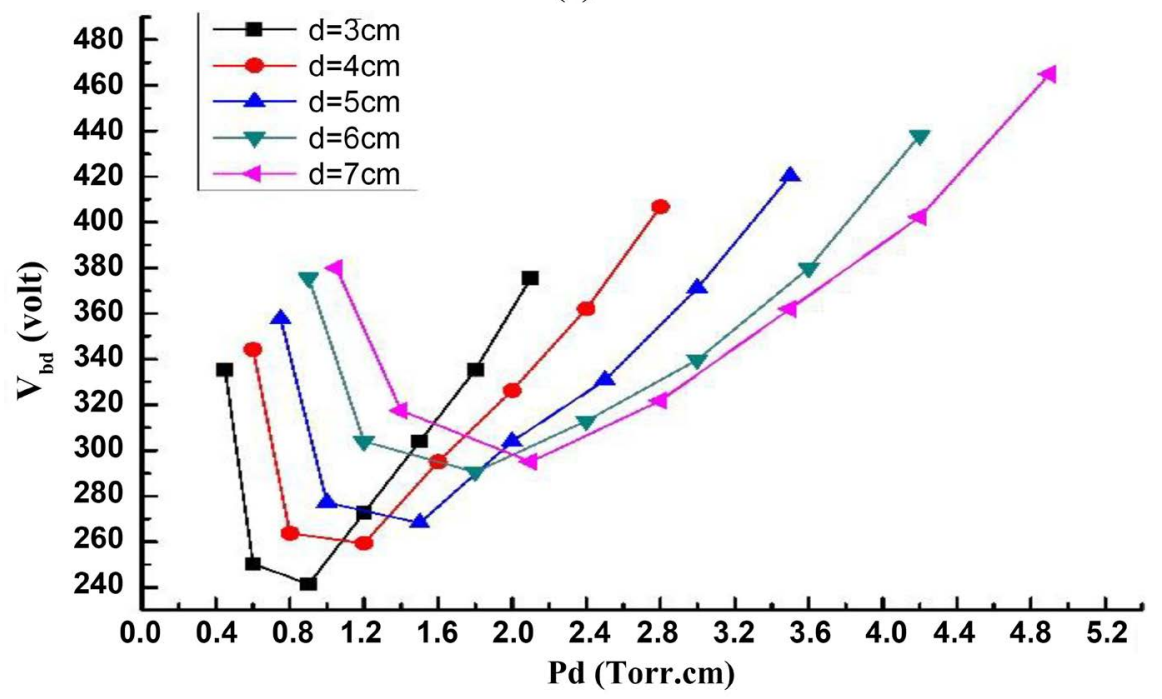

(b)

Figure 5. (a) Waveform of the breakdown voltage at $P d=4.2$ Torr.cm, and (b) Paschen curves at each gap length.

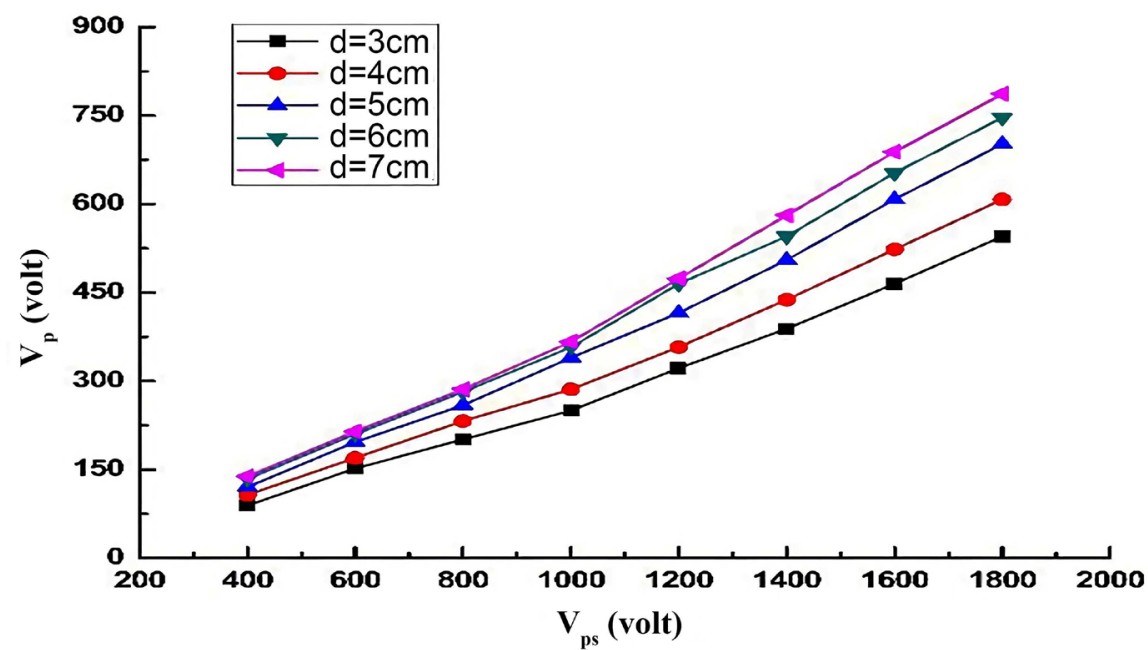

(a) 


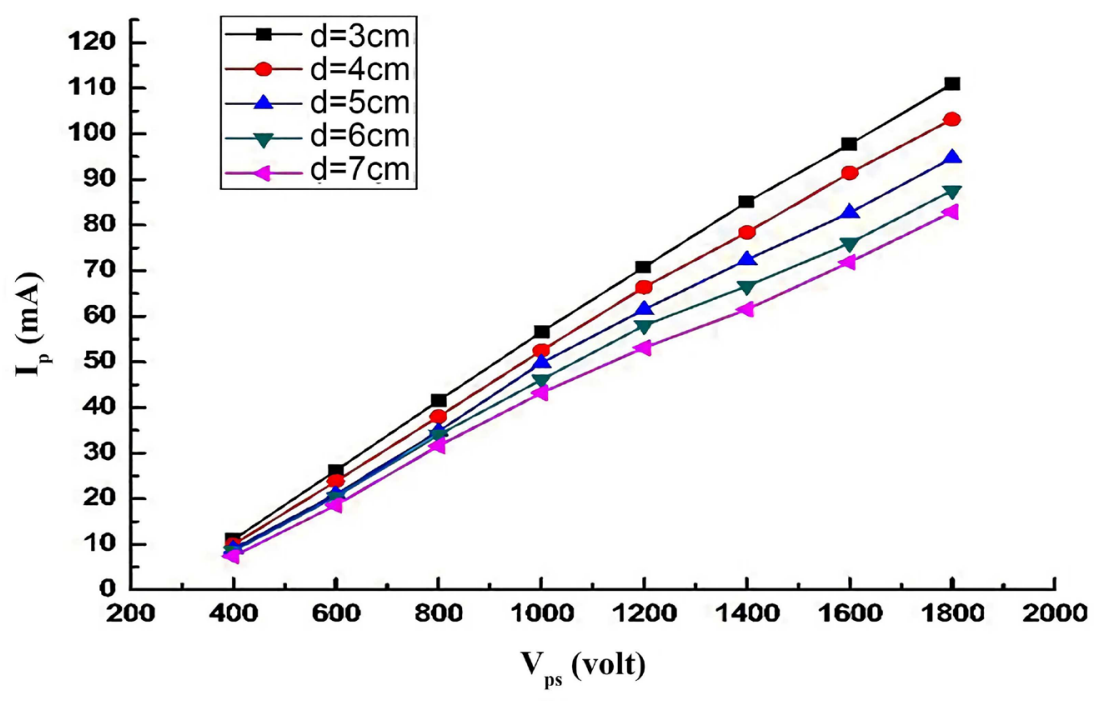

(b)

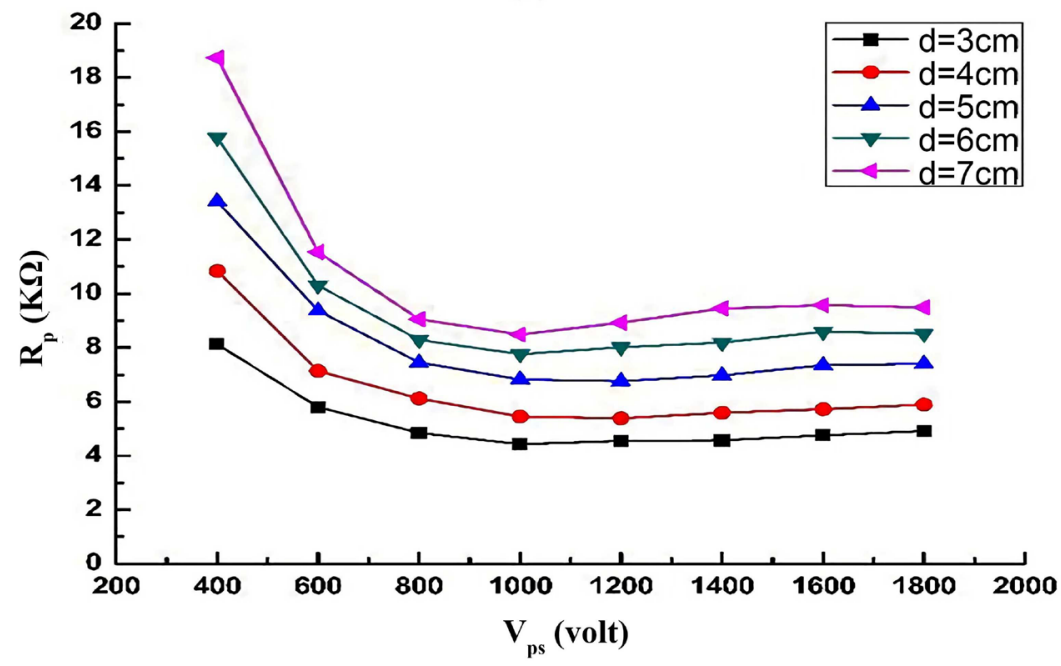

(c)

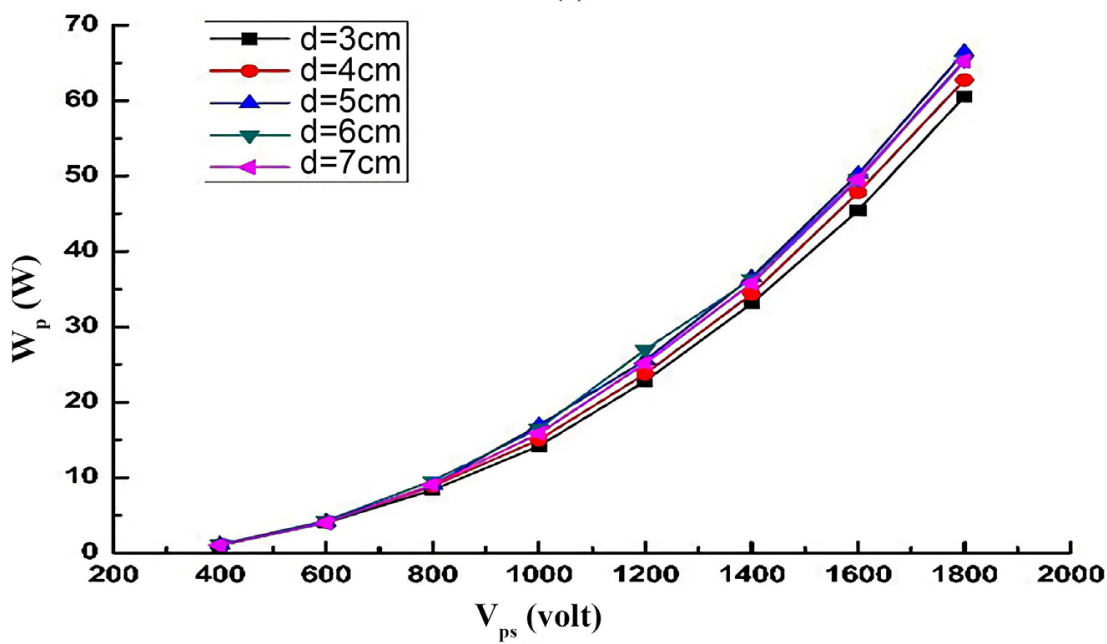

(d)

Figure 6. Shows at different gap lengths, the variation curves between the operating voltage $V_{p s}$ and the electrical plasma parameters (a) the plasma current, (b) the plasma voltage, (c) the plasma resistance and (d) the plasma power. 
increasing $V_{p}, I_{p}$ and $W_{p}$. So, $R_{p}$ is decreased with $V_{p s}$, because the resistance is inversely proportional to the current, until $V_{p s}=1000$ volt, after that it was almost constant. This is because of the rate of variation $V_{p}$ and $I_{p}$ nearly constant.

2) For all below curves, there is almost no affecting change $(d)$ in the region of variation $V_{p s}$ from 400 to 1000 volt because the operating voltage in this region ionized the same number of Ar gas nearly. From 1000 volt the effect of this variation is clear because increasing the ionized numbers of Ar atoms leads to increasing the gap length.

3) From these results, the place where the samples exposed to the plasma radiation was defined $(d=5 \mathrm{~cm})$, which is considered the center of the chamber.

\subsection{Electron Temperature and Ion Density of Theplasma}

The electron temperature $\left(k T_{e}\right)$ and ion density $\left(n_{i}\right)$ of plasma were appointed at various radial distances $(r=2$ to $8 \mathrm{~cm})$, for each gap lengths $(d=3$ to $7 \mathrm{~cm})$ with operating conditions ( $P=0.3$ Torr and $I_{p}=20 \mathrm{~mA}$ ). The IV characteristic curves of the double electric probe are drawn in Figure 7 and the calculated values of the $\left(k T_{e}\right)$ and $\left(n_{i}\right)$ are tabulated in Table 1 . The results show that the highest $\left(n_{i}\right)$ and the lowest $\left(k T_{e}\right)$ occurred at $d=5 \mathrm{~cm}$ where the samples were put to study the effect of plasma on them. Table 2 is a comparison between $k T_{e}$ and $n_{i}$ which were measured in our work versus that published before. This shows that the obtained results are validated with the previous work.

\subsection{Effect of Plasma on Electronic Circuits Performance}

A double layer PCB sample with thickness $(1.55 \mathrm{~mm})$ and area $\left(15 \mathrm{~cm}^{2}\right)$ had two layers of $\mathrm{Cu}$ foil with thickness $3.5 \times 10^{-2} \mathrm{~mm}$ of each one. It was placed inside the chamber at $d=5 \mathrm{~cm}$ ( $2 \mathrm{~cm}$ from the cathode) and exposed to the plasma,

Table 1. The different values of $k T_{e}$ and $n_{i}$

\begin{tabular}{cccc}
\hline$d(\mathrm{~cm})$ & $r(\mathrm{~cm})$ & $k T_{e}(\mathrm{eV})$ & $n_{i} \times 10^{10}\left(\mathrm{~cm}^{-3}\right)$ \\
\hline & 2 & 7.96 & 1.32 \\
3 & 4 & 8.29 & 1.14 \\
& 6 & 10.44 & 0.91 \\
& 8 & 9.34 & 1.01 \\
& 2 & 6.58 & 1.58 \\
5 & 4 & 7.19 & 1.59 \\
& 6 & 7.65 & 1.62 \\
& 8 & 6.69 & 1.79 \\
& 2 & 7.48 & 1.20 \\
& 4 & 7.67 & 1.32 \\
& 6 & 7.99 & 1.26 \\
& 8 & 7.33 & 1.24 \\
\hline
\end{tabular}


Table 2. $k T_{e}$ and $n_{i}$ measured versus published.

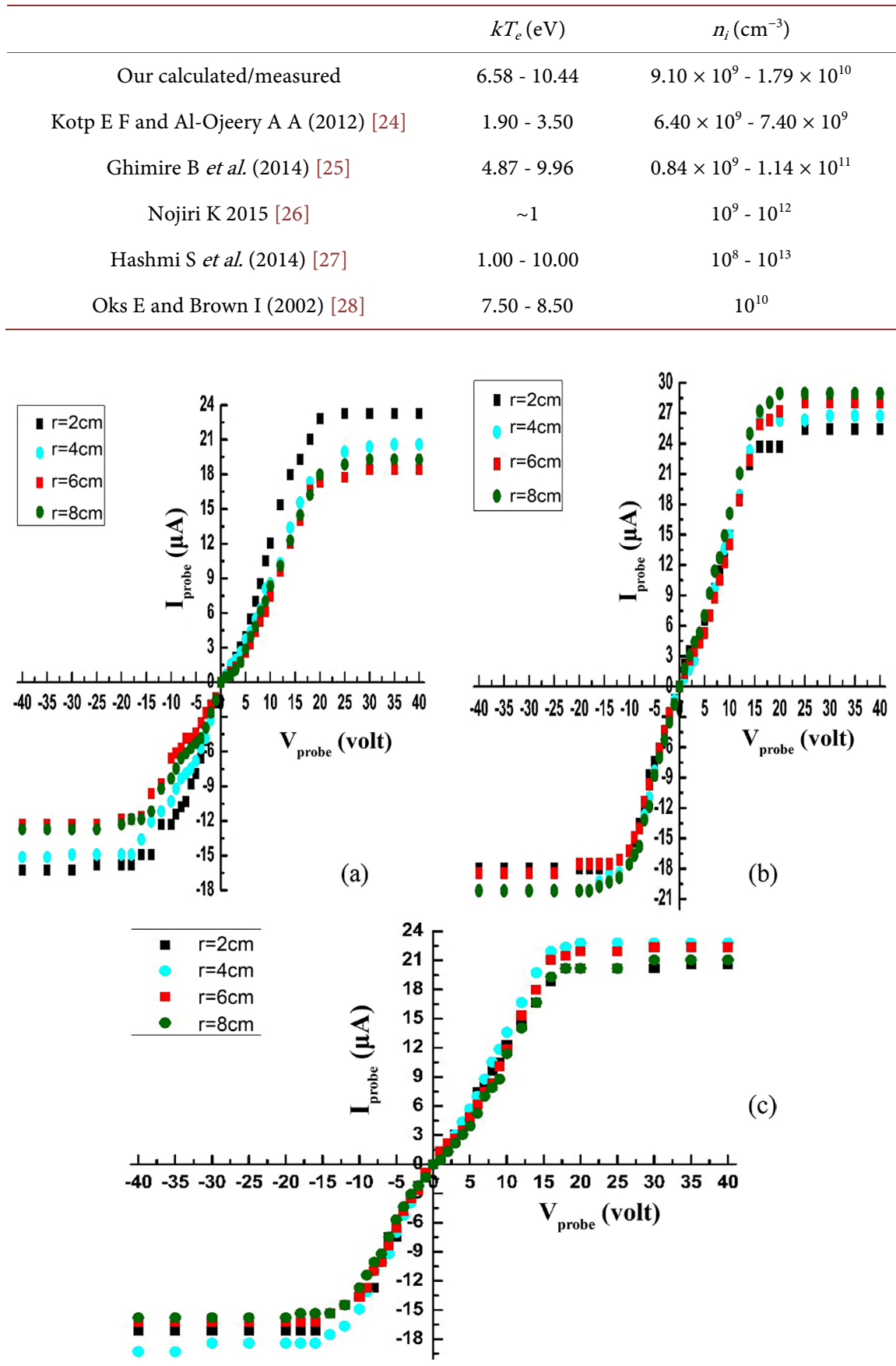

Figure 7. The IV characteristic curves at different gap lengths where (a) $d=3 \mathrm{~cm}$, (b) $d=$ $5 \mathrm{~cm}$ and (c) $d=7 \mathrm{~cm}$.

with the operating conditions ( $V_{p s}=1820$ volt, $V_{p}=805$ volt, $I_{p}=100 \mathrm{~mA}$ ), for $10 \mathrm{~min}$. Figure 8 is a photographic view shows the difference in the effect of plasma on the two sample surfaces after exposure.

The electrical resistance $(R)$ of $\mathrm{Cu}$ foil in a PCB sample was measured before and after exposure to the plasma by using the LCR meter type (TEGAM). The resistance of $\mathrm{Cu}$ foil before was $1.8 \times 10^{-2} \Omega$ while after exposure it was $0.7 \times 10^{-2}$ 


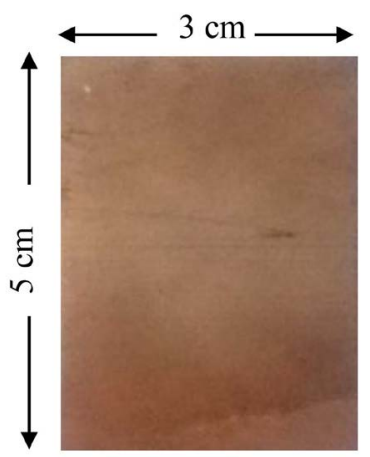

(a)

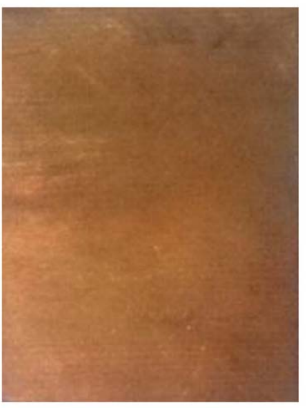

(b)

Figure 8. The photographic view of the two sides of PCB after exposed to the plasma. (a) Facing to the cathode; (b) Facing to the anode.

$\Omega$ for the layer in the front of the anode, however, the layer facing the cathode didn't have any change in its resistance. This means that the resistance of $\mathrm{Cu}$ foil after got exposed to the plasma is decreased, it allows greater current flow and the length/width (L/W) decreases [29] [30]. So, in turn, the electrical conductivity $(\sigma)$ of the $\mathrm{Cu}$ foil is increased (by using the conductivity equation [31]) from $1.6 \times 10^{6} \mathrm{~S} / \mathrm{m}$ to $4.1 \times 10^{6} \mathrm{~S} / \mathrm{m}$. So, the electronic components can be increased with the smaller size of $\mathrm{Cu}$ foil on a PCB. The reduction in the $\mathrm{Cu}$ foil size decreases the cost of PCB manufacturing which used in microelectronics applications (Integrated circuits, Cell phone, Laptop, etc.) [23].

There are many defects that may occur during printing the layout circuits on PCB. These defects are namely; breakouts, Pinhole, open-circuit, under etch, mouse bite, missing conductor, spurious copper, short-circuit, wrong side hole, conductors too close, missing hole and over etch [32]. Therefore, treating the $\mathrm{PCB}$ by exposure it to the plasma of specific characteristics is a necessary step to fix many of these problems.

Figure 9 shows the shape of the printing layout circuit on the $\mathrm{Cu}$ foil surfaces by using a digital optical microscope $(20 \times)$. It can be observed that the printing layout circuit on the $\mathrm{Cu}$ foil surface facing to the cathode after the exposure was better than that printed on the surface facing to the anode and better than that printed on the surface before exposure. This confirms that the surface adhesion forces were increased after the exposure process.

\section{Conclusions}

A cold plasma experiment was designed, established and operated at Ain Shams University (Egypt) by specifications and characteristics within the normal range of previous DC glow discharge plasma experiments in different labs around the world. The plasma is generated under a low-pressure range ( $0.15-0.70$ Torr) with a maximum dc power supply of $200 \mathrm{~W}$. The experiment consists of three main parts-the discharge chamber, the vacuum system and the powering circuit.

The cylindrical discharge chamber is made of stainless steel and has two movable 

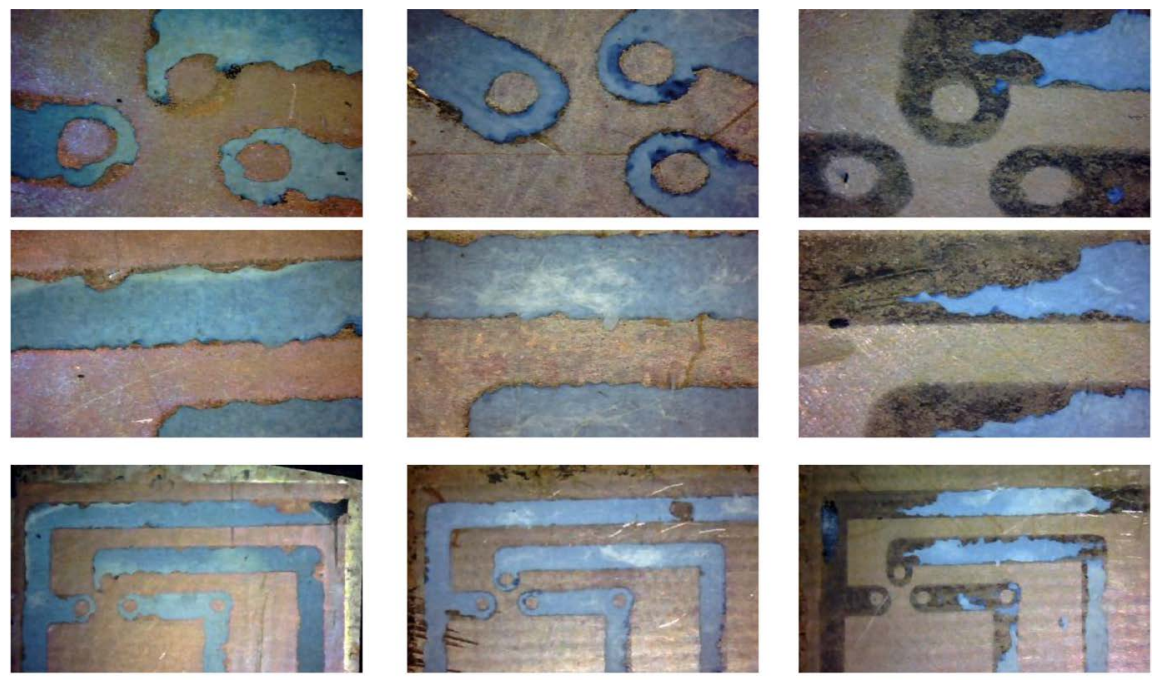

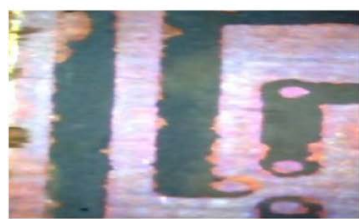

(a)

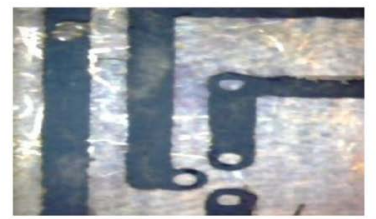

(b)

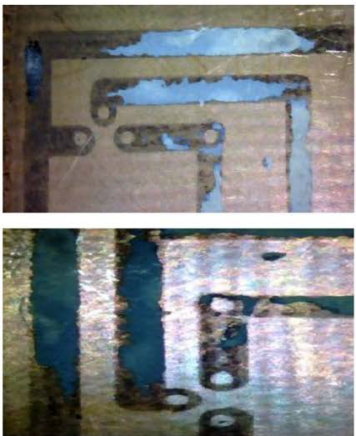

(c)

Figure 9. The circuit layout printed on the PCB. (a) Before exposure; (b) Facing to the cathode; (c) Facing to the anode.

cylindrical copper electrodes (cathode and anode), a vacuum system to evacuate the chamber before inserting the Ar gas at the operating pressure, an electric circuit that includes a power supply, potential divider, and high voltage probe.

To determine the operating conditions, the chamber was evacuated and filled it with Argon gas pressure 0.3 Torr. After that operating voltage $V_{p s}$ was applied in the range from 400 volts to 1800 volts. The experimental work included measuring the electrical plasma parameters which described the electrical properties of the produced plasma adding to the electron temperature and ion density which were appointed by a double electric probe. From it, $k T_{e}$ was in the range from $6.58 \mathrm{eV}$ to $10.44 \mathrm{eV}$ while $n_{i}$ was in the range from $9.10 \times 10^{9} \mathrm{~cm}^{-3}$ to $1.79 \times$ $10^{10} \mathrm{~cm}^{-3}$.

After validating our experimental results, we used it as a cold plasma source and studied the effect of the generated plasma on the electrical and morphological characteristics of a $\mathrm{Cu}$ foil, such as the electrical conductivity and the surface adhesive forces using a printed circuit board (PCB). The aim of this work was to improve the electronic circuits' performance that can be controlled by improvement of the electrical characteristics of a PCB. The measurements show an improvement in the electrical conductivity of a $\mathrm{Cu}$ foil and the adhesion forces of the $\mathrm{Cu}$ foil surface after plasma exposure.

The resistance of the $\mathrm{Cu}$ foil $(R)$ after being exposed to our lab generated cold plasma is found to be decreased by $61.1 \%$, i.e. the electrical conductivity of the $\mathrm{Cu}$ foil is increased by $156.25 \%$ to allow greater current to flow. Thus, the di- 
mensions (length/width) of the $\mathrm{Cu}$ trace that carries the electrical currents in the $\mathrm{Cu}$ foil in the electronic circuit of the PCB can be reduced. And in turn, the electrical conductivity $(\sigma)$ of the $\mathrm{Cu}$ foil is increased. So, the electronic components can be increased with the smaller size of $\mathrm{Cu}$ foil on a PCB. The reduction in the $\mathrm{Cu}$ foil size decreases the cost of PCB manufacturing which is used in microelectronics applications.

On the other hand, the adhesion forces of the $\mathrm{Cu}$ foil surface after exposure were increased. This helps in decreasing the loss of the PCBs because of the defective printing the layout circuits on them. And this can contribute to the reduction of the price of electronic devices, which contain PCBs, to reduce the burden on simple societies.

\section{Acknowledgements}

I wish to thank and gratitude to staff in the central physics laboratory at physics department, Faculty of Science, Ain Shams University, for their great efforts in measuring the resistance of $\mathrm{Cu}$ foil in the $\mathrm{PCB}$.

\section{Conflicts of Interest}

The authors declare no conflicts of interest regarding the publication of this paper.

\section{References}

[1] Bellan, P.M. (2008) Fundamentals of Plasma Physics. Cambridge University Press, Cambridge.

[2] Bonizzoni, G. and Vassallo, E. (2002) Vacuum, 64, 327-336. https://doi.org/10.1016/S0042-207X(01)00341-4

[3] Saad, M.M. (2013) Circuit Design of Glow Discharge Plasma Panel and Parameters Optimization. Thesis of M.Sc., Ain Shams University, Faculty of Science, Department of Physics, Cairo.

[4] Konuma, M. (1992) Film Deposition by Plasma Techniques. Springer, Berlin. https://doi.org/10.1007/978-3-642-84511-6

[5] Massarczyk, R., et al. (2016) Paschen's Law Studies in Cold Gases.

[6] Piel, A. (2010) Plasma Physics. Springer, Berlin. https://doi.org/10.1007/978-3-642-10491-6

[7] Kenneth Marcus, R. (1993) Glow Discharge Spectroscopies. Springer, Berlin.

[8] Podgornyi, I.M. (1971) Topics in Plasma Diagnostics. Springer, Berlin. https://doi.org/10.1007/978-1-4684-0724-2

[9] Uckan, T. (1987) Review of Scientific Instruments, 58, 2260-2263. https://doi.org/10.1063/1.1139332

[10] Lieberman, M.A. and Lichtenberg, A.J. (2005) Principles of Plasma Discharges and Materials Processing. Wiley-Interscience, Hoboken. https://doi.org/10.1002/0471724254

[11] Masoud, M.M. (1989) Electric Probes and New Method. Spring College on Plasma Physics, Trieste, 15 May-9 June 1989, H4-SMR 393/69. 
[12] Conde, L. (2011) An Introduction to Langmuir Probe Diagnostics of Plasmas. Madrid Dept. Física. ETSI Aeronáut ngenieros.

[13] Dahi, A., et al. (2017) Separation and Purification Technology, 187, 127-136. https://doi.org/10.1016/j.seppur.2017.05.055

[14] Gao, S., Chen, S., Ji, Z., Tian, W. and Chen, J. (2017) Advances in Mathematical Physics, 2017, Article ID: 9193149. https://doi.org/10.1155/2017/9193149

[15] Jafari, R., Asadollahi, S. and Farzaneh, M. (2013) Plasma Chemistry and Plasma Processing, 33, 177-200. https://doi.org/10.1007/s11090-012-9413-9

[16] Castillo, H.A., Restrepo-Parra, E., De La Cruz, W., Bixbi, B. and Hernandez, A. (2017) The Journal of Adhesion, 94, 615-626. https://doi.org/10.1080/00218464.2017.1320222

[17] Loureiro, J. and Amorim, J. (2016) Kinetics, and Spectroscopy of Low Temperature Plasmas. Springer International Publishing, Berlin. https://doi.org/10.1007/978-3-319-09253-9

[18] Jawaid, P., et al. (2016) Journal of Cellular and Molecular Medicine, 20, 1737-1748. https://doi.org/10.1111/jcmm.12880

[19] Duquesne, S., Magniez, C. and Camino, G. (2007) Multifunctional Barriers for Flexible Structure. Vol. 97, Springer, Berlin.

[20] Edwards, P.R. (1991) Manufacturing Technology in the Electronics Industry. Springer, Berlin. https://doi.org/10.1007/978-94-011-3130-8

[21] Chen, C.-L., et al. (2016) New Surface Treatment Method for Copper Foils to Improve Signal Integrity of Printed Circuit Board. 2016 Asia-Pacific International Symposium on Electromagnetic Compatibility, Shenzhen, 17-21 May 2016, 584-586. https://doi.org/10.1109/APEMC.2016.7522804

[22] Suzuki, O., et al. (2016) Nano Anchoring Copper Foil for Next Generation Printed Wiring Boards. 2016 Pan Pacific Microelectronics Symposium, Big Island, 25-28 January 2016, 1-6. https://doi.org/10.1109/PanPacific.2016.7428430

[23] Weiss, B., et al. (2002) Sensors and Actuators A: Physical, 99, 172-182. https://doi.org/10.1016/S0924-4247(01)00877-9

[24] Kotp, E.F. and Al-Ojeery, A.A. (2012) Journal of Basic \& Applied Sciences, 6, 817-825.

[25] Ghimire, B., Khanal, R. and Subedi, D.P. (2014) Journal of Science, Engineering and Technology, 10, 20-27.

[26] Nojiri, K. (2015) Dry Etching Technology for Semiconductors. Springer International Publishing, Berlin. https://doi.org/10.1007/978-3-319-10295-5

[27] Hashmi, S., Batalha, G.F., Van Tyne, C.J. and Yilbas, B.S. (2014) Comprehensive Materials Processing. Elsevier, Amsterdam.

[28] Oks, E. and Brown, I. (2002) Emerging Applications of Vacuum-Arc-Produced Plasma, Ion and Electron Beams. Springer, Berlin.

[29] Trace Resistance Calculator-Electrical Engineering \&amp; Electronics Tools. https://www.allaboutcircuits.com/tools/trace-resistance-calculator

[30] Ganssle, J.G. (2008) Embedded Hardware. Elsevier, Amsterdam.

[31] Bolton, W. (2006) Engineering Science. Newnes, Oxford.

[32] Khare, P., Priyadarshini, M. and Verma, M. (2017) International Journal of Engineering Technology Science and Research, 4, 30-36. 